\section{Kastamonu Eğitim Dergisi Kastamonu Education Journal}

Eylül 2019 Cilt:27 Sayı:5

kefdergi.kastamonu.edu.tr
Başvuru Tarihi/Received: 07.04.2018

Kabul Tarihi/Accepted: 29.11.2018

DOI: $10.24106 /$ kefdergi.2977

\title{
Cinsiyetin Fen Laboratuvarına Yönelik Tutum Üzerinde Etkisi: Bir Meta- Analiz Çalışması (Türkiye Örneği) ${ }^{1}$ \\ The Effect of Gender on Attitude Towards Science Laboratory: A Meta- Analysis Study (The Case of Turkey)
}

\section{Öz}

\author{
Yunus Emre BAYSAL', Fatma MUTLU
}

Bu araştırmanın amacı, fen laboratuvarına yönelik tutum üzerinde cinsiyetin etkisini belirlemek için yapılmış olan araştırma sonuçlarını meta-analiz yöntemi ile bir araya getirerek, cinsiyetin fen laboratuvarına yönelik tutum üzerindeki etki büyüklüğünü belirlemektir. Bunun için 2000-2017 yılları arasında Türkiye'de yapıımış çalışmalara ilişkin literatür taraması yapılmıştır. Literatür taraması sonucunda araştırma problemine uygun ve meta-analiz çalışmasına dahil edilebilecek istatistiksel verilere sahip yüksek lisans tezi, doktora tezi ve makaleler ulusal ve uluslararası veri tabanlarından Türkçe ve İngilizce dillerinde taranarak incelenmiştir. Bu meta-analiz çalışmasında cinsiyetin fen laboratuvarına yönelik tutum üzerinde etkisi test edilmiştir. Öncelikle literatür taraması yapılarak ilgili yayınlar bir havuzda toplanmıştr $(n=164)$. Araştırmacılar tarafindan belirlenen ölçütler doğrultusunda kodlama protokolüne uygun verileri içeren toplam 15 çalışmanın analize dahil edilmesine karar verilmiştir. Araştırmanın örneklemini 884 erkek ve 1472 kadın olmak üzere 2356 birey oluşturmaktadır. Çalışmaların etki büyüklüğü hesaplamaları; heterojenlik ve yayın yanlıı̆̆ı analizleri "Comprehensive Meta Analysis" istatistik programı kullanılarak yapılmıştır. Dahil edilen çalışmalarda heterojen bir dağılım belirlenmiştir $\left(Q=32.22 p<0.05, I^{2}=56.5\right)$. Laboratuvar yaklaşımının öğrencilerin bu derse yönelik tutumlarına ilişkin genel etki büyüklüğü değeri rastgele etkiler modeli kullanılarak -0.07 ile 0.21 güven aralığında $\mathrm{d}=0.07$ (\%95 Cl, $\mathrm{SE}=0.06$ ) olarak belirlenmiştir. Cohen, Manion ve Morrison (2007) tarafindan yapılan sınıflandırmaya göre, cinsiyet değişkeninin laboratuvar derslerine yönelik tutumu zayıf düzeyde ve kadınlar lehine etkilediği tespit edilmiştir.

Anahtar Kelimeler: laboratuvar destekli fen eğitimi, meta-analiz, cinsiyet, tutum, etki büyüklüğü.

\section{Abstract}

The aim of this study was to determine the effect of gender on attitude towards science laboratory, gather the results by using the meta-analysis method, and detect the effect size of gender on attitude towards science laboratory. In order to achieve this purpose, a literature review was carried out for the studies conducted in Turkey between 2000 and 2017. As a result literature review, postgraduate theses, doctoral dissertations, and articles, which were appropriate for the study problem and had statistical data to be included in the meta-analysis study, were reviewed and examined in Turkish and English from national and international databases. In the meta-analysis study, the effect of gender on attitude towards science laboratory was tested. Firstly the related publications were collected in a pool by carrying out the literature review $(n=164)$. In accordance with the criteria specified by the researchers, it was decided to include a total of 15 studies, containing the proper data based on the coding protocol, in the analysis. The sample of the study consisted of 2356 individuals including 884 men and 1472 women. The calculations of the effect size in the studies were performed by using "Comprehensive Meta-Analysis" statistical program for heterogeneity and publication bias analyses. A heterogeneous distribution was determined in the studies included $\left(Q=32.22 p<0.05, l^{2}=56.5\right)$. The value of general effect size of the laboratory approach concerning attitudes of the students towards this class was determined as $d=0.07(95 \% \mathrm{Cl}, \mathrm{SE}=0.06)$ at the confidence interval of -0.07 and 0.21 by using the random effect model. According to the classification by Cohen, Manion, and Morrison (2007), it was determined that the variable of gender affected the attitude towards lab classes at weak level and in favor of women.

Keywords: Laboratory based science education, meta- analysis, gender, attitude, effect size 


\section{Extended Abstract}

Science laboratories are shown as the most important active learning environment in science education. Laboratories are active learning environments where students interact with each other, generate scientific information, develop basic scientific thinking skills, and also comprehend the scientific concepts. Many studies have emphasized that laboratory applications are importantly and significantly effective in science successes of students and in developing attitudes towards science and laboratory classes. When the literature is examined, it is observed that one of the most important factors affecting the attitude towards science class and laboratory is the factor of gender. When the studies on the effect of gender on attitude towards science laboratories are examined, the studies proving that the attitude increases in favor of men or women have been found. In a great majority of the studies, it was found that there was no statistical significant difference between men and women in terms of the attitude towards the laboratory. It was observed that full consistency was not reached in all results of these studies. Even though there are studies investigating the effect of the gender variable on attitude towards science laboratory in Turkey and revealing independent, repeated or different results, any meta-analysis conducted on this matter was not found.

In this meta-analysis study, 15 studies in which total sample number was 164, including articles and dissertations conducted in Turkey were included. As a result of the review, studies in conformity with the coding protocols were included and the analyses were carried out. The studies included in the research were those conducted in Turkey between 2000 and 2017. As a result of the funnel plot prepared for determining whether or not there is publication bias in terms of the studies included in the research as well as Egger's regression Test and Begg and Mazumdar rank correlation test, no publication bias was found in the study.

The aim of this study was to synthesize the general effect of the variable of gender on attitude towards science laboratory in Turkey via the meta-analysis method. In accordance with this purpose, answer was sought for the question "What is the level of effect size of gender on attitude towards science laboratory". It was found that the distribution of the effect sizes of the studies included in the research had a heterogeneous structure according to the fixed effects model. Therefore, the random effect model was used to determine the effect of the variable of gender on attitudes of students towards laboratory in laboratory-based science education applications. According to this model, general effect size of the studies was determined as 0.07 . This value was at positive and weak level according to the effect size classification by Cohen et al. (2007). According to these results, it can be asserted that gender is an independent and determinant factor in determining the attitude towards science laboratory. As a result of the study, it was found that attitudes of female students towards science laboratory were more positive than male students. The sample of the study consisted of 2356 individuals including 884 men and 1472 women. When considered from this point of view it was thought that when numbers of female and male students in the experimental and control groups were not equal or close to each other, this may affect the results.

According to the results of the study, it was determined that the effect size of the variable of gender on attitude towards science laboratory had a positive and weak. The fact that all of the studies used in the research were conducted in Turkey makes the value of effect size determined in the research valid for Turkey. Another limitation of the research is that even though heterogeneity was determined in effect values in the study, the moderator analysis was not performed. It can be recommended to conduct future other meta-analysis studies at international level by broadening this framework and to carry out comparative related meta-analysis studies on basis of countries. 


\section{Giriş}

Fen eğitiminde aktif öğrenme ortamlarından en önemlisi olarak fen laboratuarları gösterilmektedir. Laboratuvarlar, bireylerin, öğrenme ortamında birbirleriyle etkileşimde bulunmalarının yanında, onların bilimsel bilgiyi oluşturdukları ve temel bilimsel düşünme becerilerini geliştirdikleri, aynı zamanda bilimsel kavramları kavradıkları aktif öğrenme ortamlarıdır (Hofstein ve Lunetta, 2003). Fen derslerinde laboratuvar kullanımı öğrencilere; gözlem yapma, sınıflama, ölçüm yapma gibi temel bilimsel süreç becerileri kazandırmanın yanı sıra tahminde bulunma, çıkarım yapma gibi nedensel süreç becerileri, hipotez kurma ve değişkenleri belirleme gibi deneysel becerilerin kazandırılmasında da büyük rol oynamaktadır (Ayas ve diğerleri, 2012). Bunun yanı sıra laboratuvarlar, öğrencilere anlamakta zorlandıkları fen konularını yaparak yaşayarak öğrenme imkanı tanıdığı için kalıcı öğrenmeye olanak sağlayan etkin bir öğrenme ortamı sağlamaktadır (Çallıca, Erol, Sezgin ve Kavcar, 2000). Fen eğitimcileri laboratuvar etkinlikleri sayesinde öğrenmenin daha nitelikli olarak gerçekleşeceğini ve hatta deneylere yer vermeksizin fen konularının tam olarak öğrenilemeyeceğini belirtmişlerdir (Hofstein and Lunetta, 1982; Çepni ve Ayvacı, 2006).

Tutum; bireylerin insanlara, nesnelere, konulara, olaylara yönelik olan zihinsel bir eğilimi olup, bilişsel, duyuşsal ve davranışsal boyutlarıyla davranışın önemli bir yordayıcısı olarak kabul edilmektedir (Ekici, 2002). Öğrenme ve öğretimde tutuma ilişkin literatür incelendiğinde derse yönelik tutumun öğrenmeyi etkileyen önemli duyuşsal faktörlerden biri olduğunu belirten araşttrmalar olduğu görülmektedir (Doğru ve Kıyıcl, 2005; Akyol ve Dikici, 2009; Gürbüzoğlu Yalmancı, 2016). Laboratuvar uygulamalarının, fen ve laboratuar derslerine karşı olumlu tutumlar geliştirmede ve fen başarılarında önemli ve anlamlı derecede etkili olduğu birçok araştırmada vurgulanmıştır (Freedman, 2001; Yenilmez ve Özabacı, 2003). Fizik (Dilber, Sönmez, Doğan ve Sezek, 2006; Ayvacı ve Yıldız, 2013; Keleş ve Özsoy, 2017), kimya (Hofstein, Shore and Kipnis, 2004; Alkan ve Erdem, 2013), biyoloji (Doğan, Sezek, Yalçın, Kıvrak, Yalçın, Usta ve Ataman, 2002;Dervişoğlu ve Acarlı, 2018), fen bilgisi (Nuhoğlu ve Yalçın, 2004; Erkol, Kışoğlu ve Gül, 2017) ve sınıf öğretmenliği öğrencileri (Karatay, Doğan ve Şahin, 2014) gibi farklı örneklem gruplarına ait yapılan çalışmalar, laboratuvar uygulamalarının laboratuvara yönelik tutumunu etkilediği yönündedir.

Alan yazın incelendiğinde, fen derslerine ve laboratuvara yönelik tutuma etki eden faktörlerin en önemlilerinden birinin cinsiyet faktörü olduğu görülmektedir (Yeşilyurt, Kurt ve Temur, 2005; Azizoğlu ve Çetin, 2009). Cinsiyetin laboratuvara yönelik tutum üzerinde etkisi ile ilgili yapılan araştrmalar incelendiğinde; erkekler (Keskin Geçer ve Zengin, 2015) yada kadınlar lehine tutumun arttı̆ı sonucuna ulaşılan çalışmalara (Açışlı, Metin ve Kolomuc, 2012) rastlanmaktadır. Diğer taraftan istatistiktiksel olarak anlamlı olmasa da fen laboratuarına yönelik, kadınların (Ekici, 2002; Yeşilyurt, Kurt ve Temur, 2005; Paliç ve Pırasa, 2012;Taşlıdere ve Korur, 2012; Karademir ve Balbağ, 2015; Aka, 2016; Kırılmazkaya, 2017) yada erkeklerin (Çakmak, 2008; Yenice, Balım ve Aydın, 2008; Paliç ve Altun, 2011) daha olumlu tutumlar geliştirdiğini belirten çalışmalar da bulunmaktadır. Çalışmaların çok büyük bir çoğunluğunda ise laboratuvara yönelik tutum açısından kadın ve erkekler arasında istatistiksel olarak anlamlı bir fark bulunmamıştır (Yalvaç ve Sungur, 2000; Koray, Yaman ve Altunçekiç, 2004; Karademir ve Balbağ, 2015). Tüm bu çalışma sonuçlarında tam tutarlılığa ulaşılmadığı görülmektedir.

Görüldüğü gibi Türkiye'de cinsiyet değişkeninin fen laboratuvarına yönelik tutum üzerine etkisinin incelendiği bağımsız ve birbirinden farklı sonuçlara ulaşan araştırmalar olmasına karşın, bu konuda yapılmış bir meta-analiz çalışmasına rastlanmamıştır. Literatürde meta-analiz, belirli bir konuda yapıımış, birbirinden bağımsız, birden çok çalışmanın sonuçlarını birleştiren ve ilgili çalışmalarda elde edilen bulguların istatistiksel analizlerini yapan bir analiz yöntemidir (Akgöz, Ercan ve Kan, 2004; Yeşilyurt, 2010).

\section{Araştırmanın Amacı}

Bu araştırmada, cinsiyet değişkeninin Türkiye'de fen laboratuvarına yönelik tutum üzerinde genel etkisinin meta-analiz yöntemiyle incelenmesi amaçlanmaktadır. Bu amaç doğrultusunda cinsiyetin fen laboratuvarına yönelik tutum üzerindeki etki büyüklüğü ne düzeydedir? Sorusuna cevap aranmıştır.

\section{Yöntem}

Bu bölümde; çalışmada kullanılan araştrma modeli, verilerin toplanması ve alanyazı tarama, dahil edilme ölçütleri, verilerin kodlanması, verilerin analizi ve yorumlanması başııları yer almaktadır.

\section{Araştırma Modeli}

Bu araştırmada, cinsiyetin fen laboratuvarına yönelik tutum üzerindeki etkisini inceleyen çalışmalar meta-analiz yöntemi ile incelenmiştir. Meta-analiz, bireysel araştrmaların nicel bulgularının bir araya getirilerek istatistiksel olarak yeniden analiz edilmesi işlemidir (Card, 2012). 


\section{Verilerin Toplanması ve Alanyazı Tarama}

Bu araştırmaya cinsiyet değişkeninin Türkiye'de fen laboratuvar uygulamalarına yönelik tutum üzerindeki etkilerini inceleyen makaleler, tezler; Google Akademik, Ulakbim, Yüksek Öğretim Kurulu (YÖK) Ulusal Tez Veri Merkezi ve Eric veri tabanlarında; cinsiyet ve laboratuvar (gender and laboratory), cinsiyet ve laboratuvar tutumu (gender and laboratory attitude), fen laboratuvarı ve tutum (science laboratory and attitude) anahtar kelimelerinin ingilizce karşılıkları ile birlikte taranarak dahil edilmiştir. Tarama sonucunda meta-analize dahil edilebilecek 15 çalışmaya ulaşılmıştır. Bu çalışmaların elde edilmesine ilişkin akış şeması aşağıda sunulmuştur. Toplam 164 çalışmadan meta-analize dahil edilen 15 çalışmaya nasıl indirildiğini gösteren akış diyagramı Şekil 1'de verilmiştir.

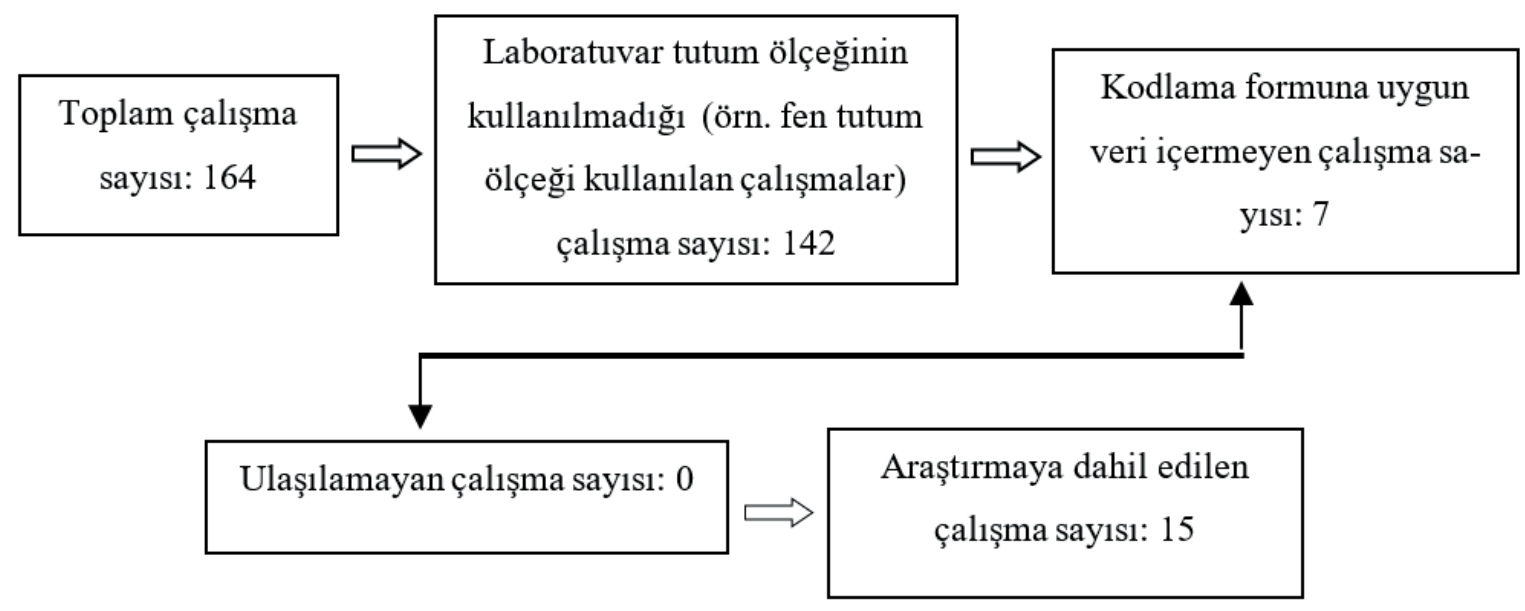

Şekil 1. Akış diyagramı

\section{Edilme Ölçütleri}

Meta-analize dahil edilen çalışmaların seçiminde kullanılan ölçütler, araştırma sınırları içerisinde olma ve analiz için gerekli istatistik verilere sahip olmayla ilgilidir (Wolf, 1986). Bu araştırmaya dahil edilen çalışmalar aşağıdaki ölçütlere göre yapılmıştr.

1.Ölçüt: Çalışmaların 2000-2017 yılları arasında yapılmış olması,

2.Ölçüt: Yayınlanmış veya yayınlanmamış yüksek lisans ve doktora tezleri, bilimsel dergilerde yayınlanan makaleler, bildiri tam metinleri,

3.Ölçüt: Meta-analize dahil edilecek çalışmalarda laboratuar tutum ölçeğinin kullanılmış olması,

4. Ölçüt: Çalışmaların Türkiye'de yapılmış olması,

5.Ölçüt: Etki büyüklügünü hesaplayabilmek için çalışmaların yeterli sayısal veri içermesi (örneklem büyüklüğü (n), ortalama puan (X), standart sapma değerleri).

Bu araştırmada analize dahil edilmeyen çalışmalar, fen laboratuvar uygulamalarının tutum üzerindeki etkisini incelemeyen, laboratuvar tutum ölçeğinin yada cinsiyet değişkeninin kullanılmadığı çalışmalardır.

\section{Kodlama Yöntemi}

Meta-analize alınan çalışmaların bilgilerini sınıflandırıp veri oluşturabilmek için kodlama yöntemi kullanılmıştr. Araştırmada çalışmaların meta-analize dahil edilme ölçütlerine uygun olup olmadığının anlaşılması ve meta-analizde çalışmalar arasında karşılaştırma yapılabilmesi için çalışmanın amacına uygun olarak bir kodlama formu düzenlenmiştir. Kodlama formunda bulunan bazı özellikler şunlardır: Çalışmanın adı, çalışmanın yazarı, çalışmanın türü, çalışmanın yayınlandığı yıl, çalışılan fen alanı, çalışmada kullanılan çalışma modeli, çalışmanın uygulandığı öğrenim düzeyi ve çalışmadaki istatistiki veriler. 15 Aralık 2017 tarihli yapılan son taramaya göre, araştırmanın dahil edilme ölçütleri dikkate alınarak 1 yüksek lisans tezi ve 14 bilimsel makale olmak üzere toplamda 15 araştırma meta-analize dahil edilmiştir. 


\section{Verilerin Analizi}

Meta-analiz çalışmasında, nicel veriler aracılığıyla etki büyüklükleri (effect size) hesaplanır. Etki büyüklüğü bir çalışmadaki ilişkinin güç ve yönünü belirlemede kullanılan standart bir ölçü değeridir (Başol-Göçmen, 2004). Çalışmada ise etki büyüklüğünün hesaplanmasında Cohen's d kullanılmıştır (Cohen, 1988). Çalışmada, etki büyüklüklerinin karşılaştrılmasında etki büyüklüğü sınıflaması kullanılmış, her araştırmaya ait etki büyüklükleri ile varyansları ve grupların karşılaştırmaları meta-analiz için Comprehensive Meta Analysis (CMA) istatistik paket programı kullanılarak hesaplanmıştır (Borenstein, Hedges, Higgins and Rothstein, 2005). CMA programı genel etki büyüklüğü, yayın yanlılığı, orman grafiği (forest plot) ve huni grafiği (Funnel Plot) grafiklerinin çizimi için kullanılmıştır.

Meta-analiz çalışmalarında etki büyüklüğünün hesaplanmasında sabit ve rastgele etki modeline karar vermek ve çalışmalar arasındaki heterojenliği ölçmek için $Q$ istatistiği kullanılmaktadır (Üstün ve Eryılmaz, 2014). Ayrıca etki büyüklüğüne ilişkin toplam varyans oranını veren $\mathrm{I}^{2}$ değeri heterojenlik hakkında bilgi vermektedir. Higgins ve Thompson (2002), heterojenlik düzeylerini: \%25 (düşük heterojen); \%50 (orta heterojen); \%75 (yüksek heterojen) olarak önermişlerdir.

\section{Etki büyüklüğü, ölçüm çeșidi ve yorumlanması}

Etki büyüklüğü, meta-analize dahil edilen her bir çalışmada, bağımsız değişkenin bağımlı değişkeni olumlu ya da olumsuz ne kadar etkilediğini gösteren bir katsayıdır (Dinçer, 2014). Literatürde etki büyüklüğü hesaplamalarında sabit etkiler modeli (SEM) ve Rastgele Etkiler Modeli (REM) olmak üzere iki model sıklıkla kullanılmaktadır. Meta-analizde model seçimini etkileyen bir diğer ölçüt $Q$ ve $I^{2}$ istatistiğidir. $Q$ istatistiği heterojenliği sınamakta, $I^{2}$ ise bu heterojenliğin ne kadar olduğunu tayin etmektedir. Analiz sonucunda $Q$ değerinin ki-kare değerinden büyük olması çalışmaların heterojen olduğu anlamına gelmektedir (Borenstein, Hedges, Higgins ve Rothstein, 2009). Meta-analiz sonucunda elde edilen etki büyüklüklerinin yorumlanmasında ise Cohen, Manion ve Morrison'un (2007) sınıflandırmalarından yararlanılmıştr.

\section{Yayın yanlılığı}

Bu araştrrmada meta-analize dahil edilen çalışmalarda yayın yanlılığı olup olmadığı Egger'in regresyon testi, Begg ve Mazumdar sıralama korelasyon testi ve huni grafiği ile test edilmiştir.

\section{Bulgular}

\section{Çalışma Karakteristikleri}

Bu bölümde araştırmaya dahil edilen çalışmaların yayın yılı, yayın türü, çalışılan fen alanı, kullanılan çalışma modeli ve öğrenim düzeyine ait frekans ve yüzde değerleri Tablo 1'de verilmiştir.

\begin{tabular}{lcc}
\hline Değişken & Çalışma Sayısı & Yüzde (\%) \\
\hline Yayın Yılı & 1 & \\
2002 & 1 & 6.6 \\
2004 & 1 & 6.6 \\
2005 & 2 & 6.6 \\
2008 & 2 & 13.3 \\
2011 & 3 & 13.3 \\
2012 & 1 & 20 \\
2014 & 2 & 6.6 \\
2015 & 1 & 13.3 \\
2016 & 1 & 6.6 \\
2017 & & 6.6 \\
\hline Yayın Türü & 14 & 93.3 \\
Makale & 1 & 6.7 \\
Yüksek Lisans Tezi & - & \\
Doktora Tezi & & \\
\hline
\end{tabular}




\begin{tabular}{lcc}
\hline Değişken & Çalışma Sayısı & Yüzde (\%) \\
\hline Fen Alanı & 8 & \\
Fen Bilgisi & 5 & 53.3 \\
Fizik & 2 & 33.4 \\
Biyoloji & - & 13.3 \\
Kimya & & \\
\hline Çalışma Modeli & 13 & \\
Tarama Modeli & 2 & 86.7 \\
Deneysel Model & & 13.3 \\
\hline Öğrenim Düzeyi & 2 & 13.3 \\
Ilköğretim & - & - \\
Ortaöğretim & 10 & 66.7 \\
Lisans & 3 & 20 \\
Öğretmen & & \\
\hline
\end{tabular}

Tablo 1 incelendiğinde, yayın yılı değişkeni boyutunda çalışmaların 2008-2017 yılları arasında; yayın türü değişkeninde makale (\%93.3); fen alanı değişkeninde fen bilgisi (\%53.3); çalışma modeli değişkeni boyutunda tarama modeli (\%86.7) ve uygulama düzeyinde ise lisans alanında (\%66.7) çalışma sayılarının daha fazla olduğu görülmektedir.

\section{Yayın Yanlıı̆ı̆ı Bulguları}

Yayın yanlılığı (publication bias), sadece anlamlı sonuçlara ulaşımış ve yayınlanmış çalışmaların meta-analize dahil edilmesi, anlamlı sonuçları bulunmayan ve yayınlanmamış çalışmaların meta-analize dahil edilmemesi sonucu oluşan bir durumdur (Şen ve Akbaş, 2016). Bu çalışmada yayın yanlıı̆ını belirlemede huni saçılım grafiği kullanılmıştı (Şekil 2).

Huni saçılım grafiği incelendiğinde, 2 adet çalışma dışında çalışmaların huninin içinde olduğu görülmektedir. Borenstein ve ark. (2009)'na göre, huni saçılım grafiğinde çalışmaların huninin içinde ve simetrik olması durumunda yayın yanııı̆̆ııı olmadığı anlamına gelmektedir. Bu bağlamda grafik değerlendirildiğinde çalışmaların çoğunluğunun huninin içinde olması yayın yanlılığının olmadığı fikrini vermektedir. Fakat grafikte tam bir simetrinin olmaması durumunda yayın yanlılı̆ını değerlendirmede diğer testlere de bakılması gerekmektedir. Ancak grafikten istatistiksel bilgi alınamadığı için çalışma örnekleminin yanlı seçilmediğini istatistiksel olarak ortaya koyacak Begg ve Mazumdar sıralama korelasyon testi (Begg ve Mazumdar, 1994) ile Egger'ın doğrusal regresyon testine (Egger, Smith, Schneider ve Minder, 1997) de başvurulmuştur. Bu testlerin sonuçları Tablo 2'de verilmiştir.

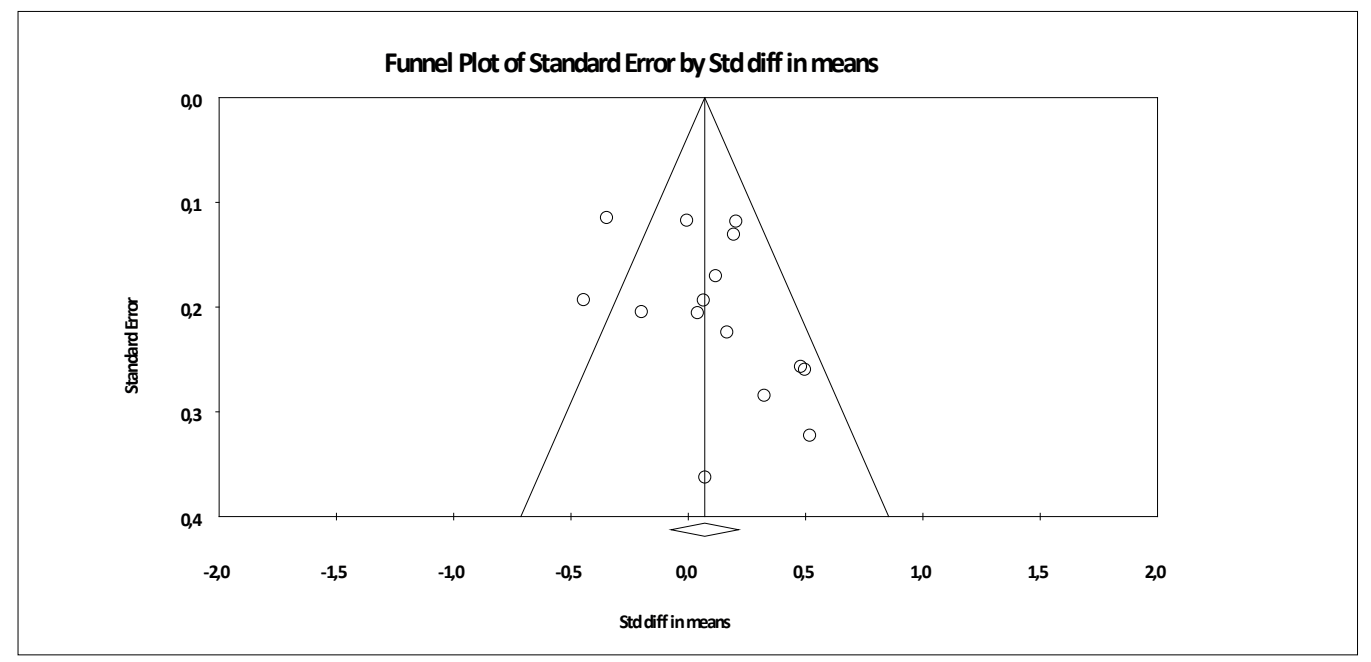

Şekil 2. Etki büyüklüklerinin huni saçılım grafiği 
Tablo 2. Egger Regresyon Testi ile Begg ve Mazumdar Sıra Korelasyon Testi Sonuçları

\begin{tabular}{cccc}
\hline Egger Regresyon Testi & \multicolumn{2}{c}{ BeggMazumdar Sıra Korelasyonu } \\
\hline t değeri & 1.45 & Tau & 0.29 \\
df & 13 & Z değeri & 1.53 \\
P değeri (Tek Kuyruklu) & 0.08 & P değeri (Tek Kuyruklu) & 0.06 \\
\hline
\end{tabular}

Tablo 2'de incelendiğinde Begg ve Mazumdar sıra korelasyonu testleri sonucuna (Tau=0.29 z=1.53; $p=0.12 ; p>0.05$ ) göre yanlılık olmadığı söylenebilir. Egger regresyon testi sonucunda ise benzer şekilde $p$ değerlerinin (çift kuyruklu) 0.05 'ten büyük olması $(p=0.16)$ bu çalışmada yayın yanlııı̆ının olmadığını göstermektedir.

\section{Genel Etki Büyüklüğü Bulguları}

Meta-analiz çalışmalarında etki büyüklüğünü hesaplayabilmek için öncelikle model seçimine karar vermek, dolayısıyla homojenlik testinin yapılması gerekmektedir. Homojenlik testi sonuçları Tablo 3'te sunulmuştur.

Tablo 3. Sabit etkiler modeline göre çalışmaların homojenlik testine ait bulgular

\begin{tabular}{ccccc}
\hline Homojenlik Değeri (Q) & ddf & Ki-Kare Tablo Değeri $\left(\chi^{2}\right)$ & p & I $^{2}$ Değeri (I-square) \\
\hline 32.22 & 14 & 23.69 & 0.004 & 56.5 \\
\hline
\end{tabular}

Tablo 3 incelendiğinde, çalışmaların homojenlik değeri sabit etkiler modeline göre hesaplandığında Q istatistiksel değerinin (32.22) ile \%95 anlamlılık düzeyinde 14 serbestlik dereceli ki-kare $\left(\chi^{2}\right)$ değerinden (23.68) büyük olduğu için etki büyüklükleri dağılımının heterojen bir özelliğe sahip olduğu söylenebilir. Ayrıca Q istatistiğinin bir tamamlayıcısı olan $\mathrm{I}^{2}$ değeri, \%56.5 ile orta düzeyde heterojen çıkmıştır. Bu noktadan hareketle, cinsiyet değişkeninin laboratuvara dayalı fen eğitiminin laboratuvara yönelik tutum üzerindeki etkisini belirlemek için rastgele etkiler modeli kullanılmıştır.

Tablo 4. Rastgele etkiler modeline göre etki büyüklüğüne ait bulgular

\begin{tabular}{ccccccc}
\hline Ortalama & \multicolumn{5}{c}{ \%95 Güven Aralı̆̆ı } \\
\hline Etki Büyüklüğü (ES) & $\mathbf{n}$ & Standart Hata & Alt Sınır & Üst Sınır & $\mathbf{Z}$ & $\mathbf{p}$ \\
\hline 0.07 & 15 & 0.06 & -0.07 & 0.21 & 0.95 & 0.33 \\
\hline
\end{tabular}

Tablo 4, çalışmaların rastgele etkiler modeline göre meta-analize dahil edilen 15 çalışmaya ait ortalama etki büyüklüğü \%95 güven aralığında üst sınırı 0.21 ve alt sınırı -0.07 ile ortalama etki büyüklüğü değerinin 0.07 olduğunu göstermektedir ( $z=0.95 ; p=0.33$ ). Bu değer Cohen ve ark. (2007) sınıflandırmasına göre zayıf etki büyüklüğü aralığında yer almaktadır. Dolayısıyla cinsiyet değişkeni fen laboratuvar tutumu üzerinde zayıf bir etkiye sahiptir.

\begin{tabular}{|c|c|c|c|c|c|c|c|c|c|}
\hline \multirow[t]{2}{*}{ Calisma Adi } & \multirow[b]{2}{*}{$\begin{array}{l}\text { Std diff } \\
\text { in means }\end{array}$} & \multirow[b]{2}{*}{$\begin{array}{l}\text { Standard } \\
\text { error }\end{array}$} & \multicolumn{3}{|c|}{ Statistics for each study } & \multirow[b]{2}{*}{ Z-Value } & \multirow[b]{2}{*}{ p-Value } & \multicolumn{2}{|c|}{ Sample size } \\
\hline & & & Variance & $\begin{array}{l}\text { Lower } \\
\text { limit }\end{array}$ & $\begin{array}{c}\text { Upper } \\
\text { limit }\end{array}$ & & & Kadın & Erkek \\
\hline Çakmak, 2008 & $-0,01$ & 0,12 & 0,01 & $-0,24$ & 0,23 & $-0,04$ & 0,96 & 115 & 196 \\
\hline Dogru ve ark., 2011 & 0,04 & 0,21 & 0,04 & $-0,36$ & 0,44 & 0,20 & 0,84 & 51 & 44 \\
\hline Ince Aka, 2016 & 0,20 & 0,12 & 0,01 & $-0,03$ & 0,44 & 1,73 & 0,08 & 350 & 90 \\
\hline Karademir ve Balbag, 2015 & 0,07 & 0,36 & 0,13 & $-0,64$ & 0,78 & 0,20 & 0,84 & 49 & 9 \\
\hline Karatay ve ark., 2014 & 0,12 & 0,17 & 0,03 & $-0,22$ & 0,45 & 0,69 & 0,49 & 173 & 43 \\
\hline Keskin Geçer ve Zeng in, 2015 & $-0,45$ & 0,19 & 0,04 & $-0,82$ & $-0,07$ & $-2,30$ & 0,02 & 52 & 58 \\
\hline Kirilmazkaya, 2017 & 0,52 & 0,32 & 0,10 & $-0,11$ & 1,15 & 1,61 & 0,11 & 29 & 15 \\
\hline Paliç ve Altun, 2011 & 0,50 & 0,26 & 0,07 & $-0,01$ & 1,01 & 1,91 & 0,06 & 45 & 23 \\
\hline Paliçve Pirasa, 2012 & 0,48 & 0,26 & 0,07 & $-0,02$ & 0,98 & 1,87 & 0,06 & 44 & 24 \\
\hline Taslidere ve Korur, 2012 & 0,19 & 0,13 & 0,02 & $-0,06$ & 0,45 & 1,49 & 0,14 & 140 & 101 \\
\hline Yenice ve ark., 2008 & $-0,20$ & 0,20 & 0,04 & $-0,60$ & 0,20 & $-0,97$ & 0,33 & 105 & 31 \\
\hline Yesilyurt ve ark., 2005 & 0,17 & 0,22 & 0,05 & $-0,27$ & 0,61 & 0,74 & 0,46 & 32 & 53 \\
\hline Ekici, 2002 & 0,07 & 0,19 & 0,04 & $-0,31$ & 0,45 & 0,34 & 0,73 & 60 & 48 \\
\hline Koray ve ark., 2004 & 0,32 & 0,28 & 0,08 & $-0,23$ & 0,88 & 1,14 & 0,25 & 25 & 25 \\
\hline Açisli ve ark., 2012 & $-0,35$ & 0,11 & 0,01 & $-0,57$ & $-0,12$ & $-3,02$ & 0,00 & 124 & 202 \\
\hline Rastgele Etkiler Modeli & 0,07 & 0,07 & 0,01 & $-0,07$ & 0,21 & 0,96 & 0,34 & & \\
\hline
\end{tabular}

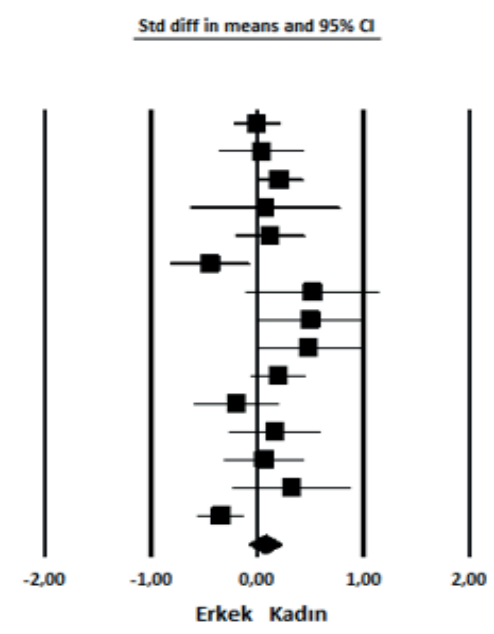

\section{Şekil 3. Çalışmaların etki büyüklüklerini gösteren orman grafiği}

Şekil 3, rastgele etkiler modeline göre çalışmaların etki büyüklüklerine ait orman grafiğini (forest plot) göstermektedir. Orman grafiğinde görülen siyah kareler o çalışmanın gözlenen etki büyüklüğünü, her karenin iki yanındaki yatay çizgiler ise o çalışmaya ait etki büyüklüğünün \%95'lik güven aralığını göstermektedir. Burada yatay çizgilerin uzunluğu güven 
aralığının genişliğini belirtmektedir. Tüm karelerin en alt kısmında bulunan eşkenar dörtgen tüm çalışmaların genel etki büyüklüğünü göstermektedir (Ayaz ve Söylemez, 2015). Şekil 3; Kırılmazkaya (2017)'ya ait çalışmanın 1.442 ile en geniş güven aralığına; Keskin Geçer ve Zengin (2015)'e ait çalışmanın ise -0.45 ile küçük güven aralığına sahip olduğunu göstermektedir. Diğer taraftan araştırmaya dahil edilen 4 çalışmanın etki büyüklüklerinin negatif kalan diğer 11 çalışmanın etki büyüklüklerinin ise pozitif olduğu görülmektedir. Toplam örneklem sayısının (n) 2356 olduğu bu çalışmaların etki büyüklüklerinin alt sınırı -0.64 ile -0.07 arasında üst sınırı ise -0.07 ile 0.98 arasında değişmektedir. Cinsiyet değişkeninin fen laboratuvar derslerine yönelik tutumu, zayıf düzeyde ve kadınlar açısından daha olumlu etkilediği tespit edilmiştir.

\section{Sonuç ve Tartışma}

Bu meta-analiz çalışmasına Türkiye'de yapılan makale ve tezler olmak üzere toplam örneklem sayısının 164 olduğu 15 çalışma dahil edilmiştir. Tarama sonucunda kodlama protokollerine uygun çalışmalar alınmış ve analizler gerçekleştirilmiştir. Araştırmaya alınan çalışmalar 2000-2017 yılları arasında ülkemizde yapılmış araştrrmalardır. Araştırmaya dahil edilen çalışmalar açısından yayın yanlılığının olup olmadığının belirlenmesi için oluşturulan huni saçılım grafiği, Egger'in Regresyon Testi, Begg ve Mazumdar sıralama korelasyon testi sonucu araştırmada yayın yanlıığının olmadığı bulunmuştur.

Araştrrmanın problem cümlesi “cinsiyetin fen laboratuvarına yönelik tutum üzerindeki eki büyüklüğü ne düzeydedir? Şeklindedir. Araştırmaya dahil edilen çalışmaların etki büyüklükleri dağıımının sabit etkiler modeline göre heterojen yapıya sahip olduğu saptanmıştr. Bu sebeple cinsiyetin laboratuvara yönelik tutum üzerindeki etkisini belirlemek için rastgele etkiler modeli kullanılmıştır. Bu modele göre çalışmaların genel etki büyüklüğü 0.07 olarak tespit edilmiş olup, cinsiyet değişkenin fen laboratuvar tutumu üzerinde zayıf bir etkiye sahip olduğu belirlenmiştir. Diğer taraftan tespit edilen etki büyüklüğünün daha yüksek düzeyde çıkmamasının sebebi olarak tutum gibi duyuşsal değişkenlerde değişim meydana gelebilmesi için uzun vadeli bir çalışmaya ihtiyaç duyulması gösterilebilir (Baran ve Maskan, 2009; Duru, Demir, Önen ve Benzer, 2011).

Çalışma sonucunda kadınların fen laboratuvarına yönelik tutumlarının erkek öğrencilere göre daha olumlu olduğu söylenebilir. Elde edilen bu sonuç, yapılan bireysel araştırmalar ile tutarlılık göstermektedir (Ekici, 2002; Yeşilyurt, Kurt ve Temur, 2005; Açışlı, Metin ve Kolomuc, 2012; Paliç ve Pırasa, 2012; Taşlıdere ve Korur, 2012; Karatay, Doğan ve Şahin, 2014; Karademir ve Balbağ, 2015; Aka, 2016; Kırılmazkaya, 2017). Araştırmanın örneklemini 884 erkek ve 1472 kadın olmak üzere 2356 birey oluşturmaktadır. Bu açıdan bakıldığında deney ve kontrol gruplarında kadın ve erkek öğrenci sayılarının eşit ya da yakın sayıda olmamasının sonuçları etkileyebileceği düşünülmektedir.

Diğer taraftan cinsiyetin laboratuvara yönelik tutum üzerinde etkisi ile ilgili yapılan araşttrmalar incelendiğinde; erkekler (Keskin Geçer ve Zengin, 2015) yada kadınlar lehine tutumun arttğı sonucuna ulaşılan çalışmalara (Açışlı, Metin ve Kolomuc, 2012) rastlanmaktadır. Ancak istatistiktiksel olarak anlamlı olmasa da fen laboratuarına yönelik, kadınların (Ekici, 2002; Yeşilyurt, Kurt ve Temur, 2005; Paliç ve Pırasa, 2012; Taşııdere ve Korur, 2012; Karatay, Doğan ve Şahin, 2014; Karademir ve Balbağ, 2015; Aka, 2016; Kırılmazkaya, 2017) yada erkeklerin (Yenice, Balım ve Aydın, 2008; Paliç ve Altun, 2011) daha olumlu tutumlar geliştirdiğini belirten çalışmalar da bulunmaktadır. Çalışmaların çok büyük bir çoğunluğunda ise laboratuvara yönelik tutum açısından kadın ve erkekler arasında istatistiksel olarak anlamlı bir fark bulunmamıştır (Yalvaç ve Sungur, 2000; Koray, Yaman ve Altunçekiç, 2004; Karademir ve Balbağ, 2015). Bu bulgunun nedeni olarak eğitim-öğretimde firsat ve imkanların eşit şekilde sunulması gösterilebilir. Bazı araştırmalarda cinsiyete göre anlamlı farklıık görülürken, bazı araştırmalarda anlamlı farklılık görülmemesinin sebebi örneklem grubundaki bireylerin yaş durumu ve buna bağlı olarak algılamalarındaki farklılıktan kaynaklanmış olduğu düşünülmektedir. Bu durumun diğer bir nedeninin araştırmalardaki örneklem özelliklerinin ve ölçme araçlarının farklı olmasından kaynaklanabileceği söylenebilir. Bu sonuçlara göre, fen laboratuvarına yönelik tutumunun belirlenmesinde cinsiyetin bağımsız olup, belirleyici bir faktör olmadığı söylenebilir.

\section{5. Öneriler}

Bu araştırmadan elde edilen sonuçlara dayanılarak, aşağıdaki öneriler geliştirilmiştir:

- Meta-analiz çalışması için bir araya getirilen araştırmaların yayın türüne göre frekans ve yüzde değerlerine bakıldığında 15 çalışmadan \%93.3'ünün makalelerden oluştuğu görülmektedir. Cinsiyet değişkeninin laboratuvar destekli öğretim yönteminin tutum üzerindeki etkisini konu alan özellikle doktora tezlerinin sayısının az olması bu tür çalışmaların sayısının arttıııması gerekliliğini ortaya koymaktadır.

- Uygulama düzeyi incelendiğinde ise; çalışmaların büyük oranda lisans düzeyinde \%66.7 oranında gerçekleştirildiği tespit edilmiş, ortaöğretim kademesinde çalışmaya rastlanmamıştr. Bu nedenle bu aşamada

| Kastamonu Eğitim Dergisi, 27(5), 2019| 
bulunan öğrencilerle gerçekleştirilecek çalışma sayısının arttırılması önerilebilir.

- Çalışmada kullanılan araştırmaların tamamının Türkiye'de yapılmış olması çalışmada bulunan etki büyüklüğü değerini Türkiye için geçerli kılmaktadır. Araştırmada etki değerlerinde heterojenlik tespit edilmesine karşıık moderator analizi yapılmaması yine araştırmanın bir başka sınırlıı̆ı olarak ortaya çıkmaktadır. Başka bir çalışmada konunun dünyadaki durumuna bakılabilir ve karşılaştırma firsatı sağlanabilir.

\section{Kaynakça}

(* ile işaretlenmiş kaynaklar, meta-analize dahil edilen çalışmaları göstermektedir.)

*Açışlı, S., Metin, M. \& Kolomuc, A. (2012). The investigate attitude of primarypre-service teachers regarding science and technology laboratory. Procedia-Social and Behavioral Sciences, 46, 2168-2172.

*Aka, E. I. (2016). An investigation into prospective science teachers' attitudes towards laboratory course and self-efficacy beliefs in laboratory use. International Journal of Environmental and Science Education, 11(10), 3319-3331.

*Çakmak, M. (2008). Fen bilgisi öğretmen adaylarının laboratuvar tutumları ile fen bilgisine yönelik tutumları arasındaki ilişkinin değerlendirilmesi. Yüksek Lisans Tezi, Kafkas Üniversitesi Fen Bilimleri Enstitüsü. Kars.

*Doğru, M., Gençosman, T. \& Ataalkın, A. (2011). Examination of natural science laboratory perception levels of students at primary education grade 6 and their attitudes towards laboratory practices of natural science course. International Journal of Educational Researchers, 2(1), 17-27.

*Ekici, G. (2002). Biyoloji öğretmenlerinin laboratuvarı dersine yönelik tutum ölçeği. Hacettepe Üniversitesi Eğitim Fakültesi Dergisi, 22, 62-66.

*Karademir, E. \& Balbağ, Z. (2015). Fen bilgisi öğretmen adaylarının fizik laboratuarına yönelik tutumlarının incelenmesi. Eğitim ve öğretim Araştrrmaları Dergisi, 2, 364-373

*Karatay, R., Doğan, F. ve Şahin, Ç. (2014). Determination of attitudes of preservice teachers towards laboratory practices/öğretmen adaylarının laboratuvar uygulamalarına yönelik tutumlarının belirlenmesi. Eğitimde Kuram ve Uygulama, 10(3), 703-722.

*Keskin Geçer, A. ve Zengin, R. (2015). Science teachers' attitudes towards laboratory practises and problems encountered. International Journal of Education and Research. 3(11), 137-146.

*Kırılmazkaya, G. (2017). Fen bilgisi öğretmen adaylarının fizik laboratuvarına yönelik kaygı ve tutumlarının incelenmesi. Journals of Social and Humanities Sciences Research. 4(3), 452-461.

*Koray, Ö., Yaman, S. \& Altunçekiç, A. (2004). Yaratıcı ve eleştirel düşünmeye dayalı laboratuvar yönteminin öğretmen adaylarının akademik başarı, problem çözme ve laboratuvar tutum düzeylerine etkisi. İnönü Üniversitesi, XIII. Ulusal Eğitim Bilimleri Kurultayı, 6-9.

*Paliç, G. ve Altun, E. (2011). Fen Bilgisi Öğretmen Adaylarının Düşünme Stilleri Ille Fizik Laboratuar Tutumları Arasındaki Ilişki. In 2nd International Conference on New Trends in Education and Their Implications, Antalya. 1286-1293.

*Paliç, G. ve Pirasa, N. (2012). A study of pre-service teachers' tendency for imprudent behaviour and physics laboratory attitudes. Procedia-Social and Behavioral Sciences, 47, 823-828.

*Taşlıdere, E. \& Korur, F. (2012). Fen ve teknoloji öğretmen adaylarının fizik laboratuvarına yönelik tutumları: Mehmet Akif Ersoy Üniversitesi örneği. Mehmet Akif Ersoy Üniversitesi Eğitim Fakültesi Dergisi, 1(23), 295-318.

*Yenice, N., Balım, A. G. ve Aydın, G. (2008). Biyoloji öğretmenlerinin laboratuvar dersine $\quad$ yönelik tutumları ve teknolojik yenilikleri izleme eğilimleri. Kastamonu Eğitim Dergisi, 16(2), 469-484.

*Yeşilyurt, M., Kurt, T. \& Temur, A. (2005). illköğretim fen laboratuvarı için tutum anketi geliştirilmesi ve uygulanması. Pamukkale Üniversitesi Eğitim Fakültesi Dergisi, 17(17), 21-31.

Akgöz, S., Ercan, i. \& Kan, i. (2004). Meta-analizi. Uludağ Üniversitesi Tıp Fakültesi Dergisi, 30(2), 107-112.

Akyol, C. \& Dikici, A. (2009). Şiirle öğretim tekniğinin öğrencilerin başarı ve tutumlarına etkisi. Elemantary Education Online, 8(1), 48-56.

Alkan, F. ve Erdem, E. (2013). Kendi kendine öğrenmenin laboratuvarda başarı, hazırbulunuşluk, laboratuvar becerileri tutumu ve endişeye etkisi. Hacettepe Üniversitesi Eğitim Fakültesi Dergisi, 44, 15-26.

Ayas, A., Çepni, S., Akdeniz, A. R., Özmen, H., Yiğit, N. \& Ayvacı, H. Ş. (2012). Kuramdan uygulamaya fen ve teknoloji öğretimi (10. baskı). Ankara: Pegem A.

Ayaz, M. F. \& Söylemez, M. (2015). Proje tabanlı öğrenme yaklaşımının Türkiye'deki öğrencilerin fen derslerindeki akademik başarılarına etkisi: Bir meta-analiz çalışması. Eğitim ve Bilim, 178, 255-283.

Ayvacı, H. Ş. ve Yıldız, M. (2013). 5 E modeline uygun olarak tasarlanan laboratuvar materyaliyle gerçekleştirilen öğretim sürecinin etkililiğinin değerlendirilmesi: Işığın kırılması. Bayburt Eğitim Fakültesi Dergisi, 8(1). 1-20.

Azizoğlu, N. \& Çetin, G. (2009). 6 ve 7. sınıf öğrencilerinin öğrenme stilleri, fen dersine yönelik tutumları ve motivasyonları arasındaki ilişki, Kastamonu Eğitim Dergisi, 17(1), 171-182. 
Baran, M., ve Maskan, A. K. (2009). Proje tabanlı öğrenme modelinin fizik öğretmenliği ikinci sınıf öğrencilerinin elektrostatiğe yönelik tutumlarına etkisi. Dicle Üniversitesi Ziya Gökalp Eğitim Fakültesi Dergisi, 12, 41-52.

Başol-Göçmen, G. (2004). Meta-analizin genel bir değerlendirmesi. Sakarya Üniversitesi Eğitim Fakültesi Dergisi, 7,186-192.

Begg, C. B. \& Mazumdar, M. (1994). Operating characteristics of a rank correlation test for publication bias. Biometrics, 50(4), 1088-1101.

Borenstein, M., Hedges, L. V., Higgins, J. P. T. \& Rothstein, H. R. (2009). Introduction to meta analysis. West Sussex-UK: John Wiley \& Sons Ltd.

Borenstein, M., Hedges, L., Higgins, J. P. \& Rothstein, H. R. (2005). Comprehensive meta-analysis version 2. Englewood, NJ: Biostat.

Card, N. A. (2012). Applied meta-analysis for social science research. Newyork, London: Guilford Press.

Cohen, L., Manion, L. \& Morrison, K. (2007). Research methods in education (6th Edition). New York: Routledge.

Çepni, S. \& Ayvacı, H. Ş. (2006). Laboratuar Destekli Fen ve Teknoloji Öğretimi. Kuramdan Uygulamaya Fen ve Teknoloji Öğretimi. 5. Baskı, Pegema Yayıncılık, Ankara.

Dervişoğlu, S. ve Acarlı, D. S. (2018). Biyoloji öğretmen adaylarının bilimsel süreç becerileri ve biyoloji laboratuvarına yönelik tutumları, öz-yeterlikleri, özgüvenleri. Bilim, Eğitim, Sanat ve Teknoloji Dergisi, 2(2), 86-92.

Dilber, R., Sönmez, E., Doğan, S. \& Sezek, F. (2006). Fizik bölümü öğrencilerinin laboratuarlara karşı tutumlarının değerlendirilmesi ve karşılaştkkları sorunların tespit edilmesi üzerine bir çalışma. Çukurova Üniversitesi Eğitim Fakültesi Dergisi, 1(31), $102-109$.

Dinçer, S. (2014). Eğitim bilimlerinde uygulamalı meta-analiz. Ankara: Pegem Akademi.

Doğan, S., Sezek, F., Yalçın, M., Kıvrak, E., Yalçın, M., Usta,Y. \& Ataman, A. Y. (2002). Atatürk Üniversitesi biyoloji öğrencilerinin laboratuvar çalışmalarına ilişkin tutumları. Erzincan Üniversitesi Eğitim Fakültesi Dergisi, 5(2), 33-58.

Doğru, M. \& Kıyıcı, F.K. (2005). Fen eğitiminin zorunluluğu, (Editör: M. Aydoğdu \& T. Kesercioğlu), İ/köğretim fen ve teknoloji öğretimi (ss.1-24), Ankara: Anı Yayıncılık.

Duru, M. K., Demir, S., Önen, F. \& Benzer, E. (2011). Sorgulamaya dayalı laboratuvar uygulamalarının öğretmen adaylarının laboratuvar algısına tutumuna ve bilimsel süreç becerilerine etkisi. M. Ü. Atatürk Eğitim Fakültesi Eğitim Bilimleri Dergisi, $33,25-44$.

Egger, M., Smith, G. D., Schneider, M. \& Minder, C. (1997). Bias in meta-analysis detected by a simple, graphical test. British Medical Journal, 315(7109), 629-634.

Erkol, M., Kışoğlu, M. ve Gül, Ş. (2017). Argümantasyon tabanlı bilim öğrenme yaklaşımı rapor formatının öğretmen adaylarının başarılarına ve fen bilgisi laboratuvarına yönelik tutumlarına etkisi. ilköğretim Online, 16(2), 614-627.

Freedman, M. P. (2001). The influence of laboratory instruction on science achievement and attitude toward science among ninth grade students across gender differences. (ERIC Document Reproduction Service No: ED454070).

Gürbüzoğlu Yalmancı, S. (2016). Biyoloji tutum ölçeğinin geçerlik ve güvenirlik çalışması. PAU Eğitim Fakültesi Dergisi, 40, $248-262$. Higgins, J. \& Thompson, S. G. (2002). Quantifying heterogeneity in a meta-analysis. Statistics in Medicine, 21, 1539-1558.

Hofstein, A. \& Lunetta, V. N. (2003). The laboratory in science education: Foundations for the twenty-first century. Science education, 88(1), 28-54.

Hofstein, A. \& Lunetta, V.N. (1982). The role of the laboratory in science teaching: Neglected aspect of research. Review of Educational Research, 52(2), 201-217.

Hofstein, A., Shore, R., \& Kipnis, M. (2004). Providing high school chemistry students with opportunities to develop learning skills in an inquiry-type laboratory-A case study. International Journal of Science Education, 26, 47-62.

Keleş, Ö. ve Özsoy, S. (2017). Pre-service teachers' attitudes toward use of Vee diagrams in general physics laboratory. International Electronic Journal of Elementary Education, 1(3), 124-140.

Nuhoğlu, H. \& Yalçın, N. (2004). Fizik laboratuarına yönelik bir tutum ölçeğinin geliştirilmesi ve öğretmen adaylarının fizik laboratuarına yönelik tutumlarının değerlendirilmesi. Gazi Üniversitesi Kırşehir Eğitim Fakültesi Dergisi, 5(2), 317-327.

Şen, S. \& Akbaş, N. (2016). Çok düzeyli meta-analiz yöntemleri üzerine bir çalışma. Eğitimde ve Psikolojide Ölçme ve Değerlendirme Dergisi, 7(1), 1-17.

Üstün, U. \& Eryılmaz, A. (2014). Etkili araştırma sentezleri yapabilmek için bir araştırma yöntemi: Meta-analiz. Eğitim ve Bilim, 39(174), 1-32.

Wolf, M. F. (1986). Meta Analysis: quantitative methods for research synthesis. SAGE Publications Inc., USA, 72p.

Yalvaç, B. \& Sungur, S. (2000). Fen bilgisi öğretmen adaylarının laboratuar derslerine karşı tutumlarının incelenmesi, D.E.Ü. Buca Eğitim Fakültesi Dergisi, 12, 56-64.

Yenilmez, K. \& Özabacı, N. Ş. (2003). Yatılı öğretmen okulu öğrencilerinin matematik ile ilgili tutumları ve matematık kaygı düzeyleri arasındaki ilişki üzerine bir araştırma. Pamukkale Üniversitesi Eğitim Fakültesi Dergisi, 14(2), 132-146.

Yeşilyurt, M. (2010). Meta analysis of the computer assisted studies in science and mathematics: A sample of Turkey. The Turkish Online Journal of Educational Technology, 9(1), 123-131. 